\title{
"Warriors": Impact of a Powerful Television Drama on the Psychological Health of U.K. Bosnia Peacekeepers
}

\author{
ASANGA FERNANDO, MRCPsych, LISA HULL, MSc, NEIL GREENBERG, MD, \\ NICOLA T. FEAR, MPhil (OxON), MATTHEW HOTOPF, PhD, AND SIMON WESSELY, FRCP
}

\begin{abstract}
PURPOSE: The impact of secondary trauma, such as watching powerful images on television, on the etiology of posttraumatic stress disorder in adults remains controversial. We explored the impact of a powerful TV drama ("Warriors") on the psychological health of U.K. peacekeeping troops compared with other military personnel who also saw the program but did not deploy on the same mission.

METHODS: Psychological health (health perception, fatigue, posttraumatic stress reactions and common mental disorders) was assessed via questionnaire in a group of 1463 U.K. Armed Forces personnel before and after the televising of an award-winning dramatic reconstruction ("Warriors") of events in Former Yugoslavia, a deployment in which some of the respondents had participated (Bosnia group) and some who had not (Era group). Information was also collected on whether participants had seen Warriors. RESULTS: Those who had deployed to Bosnia were more likely to have watched the drama, and viewers were more likely to be posttraumatic stress reactions and common mental disorders cases before transmission of the program. There were few health differences between viewers and nonviewers, and Bosnia viewers and Era viewers, posttransmission. Viewing status and group status (Bosnia/Era) restricted to viewers only did not predict posttransmission health outcomes, with one exception. Group status (viewers only) was a significant predictor of posttransmission fatigue, with Bosnia viewers more likely to be cases. Additional analyses, however, revealed the same finding for nonviewers.

CONCLUSIONS: We found no evidence that those with symptoms of traumatic distress avoided watching a drama relevant to their experiences and no evidence of adverse effects on mental health.

Ann Epidemiol 2011;21:660-665. (c) 2011 Elsevier Inc. All rights reserved.
\end{abstract}

KEY WORDS: Military, Peacekeeping Posttraumatic Stress Disorder, Television.

\section{INTRODUCTION}

Posttraumatic stress disorder (PTSD) is characterized by re-experiencing a traumatic event, avoidance behaviors, and persistent increased arousal. The diagnostic criteria for PTSD allow for an etiology of both direct and indirect trauma (1). However, debate exists as to whether the current Diagnostic and Statistical Manual of Mental Disorders, Edition IV (1) criteria allow for the inclusion of secondary exposure to trauma in its definition as might result from watching traumatic images as opposed to direct involvement.

It is known that stressful films can evoke intrusive thoughts (2), and a number of studies have implicated media

From the Institute of Psychiatry, King's College London \& South London and Maudsley NHS Foundation Trust (A.F.); and King's Centre for Military Health Research, King's College London, Weston Education Centre, Guys Kings and St Thomas' School of Medicine (L.H., N.G., N.T.F., M.H., S.W.), London, United Kingdom.

Address correspondence to: Simon Wessely, FRCP, King's Centre for Military Health Research, King's College London, Weston Education Centre, Guys Kings and St Thomas' School of Medicine, Cutcombe Road, London, SE5 9RJ. Tel.: +44 (0)207 848 0448; Fax: +44 (0)207 848 5408. E-mail: simon.wessely@kcl.ac.uk.

Dr. Fernando and Lisa Hull are joint first authors.

Received March 14, 2011. Accepted March 18, 2011. Published online June 17, 2011. exposure in adverse reactions to trauma (3-5). PTSD symptoms may also develop in children in response to television programs $(2,6)$. Critics, however, assert that these symptoms do not constitute PTSD, and that television viewing does qualify as an event "outside the range of human experience" and, consequently, conclude that TV viewing cannot cause PTSD (7).

The topic has been given new impetus after the events of September 11th, 2001. Increased frequency of viewing graphic TV images of the September 11th attacks contributed to an increase in the rates of both PTSD and depression both immediately and at 4 months (3), including the development of new-onset PTSD (4). In conclusion, although adult studies remain less compelling than those in children (8), there is evidence, largely retrospective, which supports the role of media in PTSD symptomatology $(9,10)$. We report an interesting study with prospective design, which provided the authors with a fortuitous opportunity to examine possible links between media exposure and PTSD.

\section{BACKGROUND}

In November 1999, the British Broadcasting Corporation televised "Warriors," a dramatic reconstruction of the 
Selected Abbreviations and Acronyms

PTSD $=$ posttraumatic stress disorder

PTSR $=$ posttraumatic stress reaction

activities of British soldiers deployed on a United Nations peacekeeping mission in Bosnia. Starring Damian Lewis, Matthew Macfadyen, and Ioan Gruffud, it included accurate and distressing scenes and charted the development of PTSD symptoms in most of the key characters. The audience averaged 5.63 million viewers (Pippa Harris, British Broadcasting Corporation, personal communication). It subsequently won the Prix Italia and a British Academy of Film and Television Arts and was called "arguably the defining television drama of the 1990s" (11).

Before the program was televised, our research group had completed a large epidemiological study of the health of the U.K. Armed Forces in the aftermath of the 1991 Gulf War (12). For that study, we had recruited as a "control" group, a large random sample of U.K. forces who had deployed to the Former Yugoslavia on peacekeeping duties, which were the dramatic narrative for "Warriors." We used this group for a series of papers on the mental health consequences of peacekeeping, demonstrating that these operations can be as psychologically stressful as more traditional low-intensity war fighting (13-16).

It had always been our intention to follow both the Gulf and Bosnia cohorts. "Warriors" was televised while we were designing the follow-up study and thus gave us a serendipitous opportunity to record reactions to viewing the program in our sample of peacekeepers, in whom we already had data collected on traumatic exposures and mental health that predated the transmission of the program. We therefore added a short section of new questions about viewing of the program and attitudes towards it to the existing instrument.

Specifically, we tested the hypothesis that such material would have adverse effects on the mental health in those for whom the viewing material is most relevant. We also hypothesized that because of the role of avoidance in the definition of PTSD (1) that those who chose to watch the program would have less distress beforehand than those who did not watch.

\section{METHODS}

During phase 1 of our large epidemiological study, conducted between July 1997 and December 1998 and before "Warriors," was televised, a postal questionnaire survey was mailed to 12,744 U.K. Armed Forces personnel who deployed in the 1991 Gulf conflict $(n=4248)$, or in Bosnia between 1992 and 1997 ( $\mathrm{n}=4250)$, or who were serving at the time of the Gulf War but did not deploy ("Era," $\mathrm{n}=4246)$.

During 2001 and after Warriors was televised, we followed a sample of those who had taken part in phase 1 . A random sample of 3309 participants (1243 Gulf, 1141 Bosnia, and 925 Era) was contacted (15). Details of sampling and response rates have been reported elsewhere for phase 1 (12) and the follow-up phase (15). The analyses presented here are restricted to those who completed both phases of the study and to the Bosnia and Era groups only because the considerable baseline differences between the Gulf and other groups (12).

Outcome measures used in the study include fatigue, via use the Chalder Fatigue questionnaire (17); common mental disorders, via use of the General Health Questionnaire-12, a widely used measure of psychiatric morbidity, such anxiety, depression and sleeping difficulties) (18); health perception, via use of the Short Form 36 (19); and a measure of PTSD, which we have called "posttraumatic stress reaction" (PTSR). This is explained in more detail in the paragraphs to follow.

A high score for fatigue, common mental disorders, and PTSR indicates poorer health, whereas high health perception scores indicate better health perception. "Caseness" variables were generated for each outcome. A cut-off of 4 or more was used to identify cases on the Fatigue Questionnaire and General Health Questionnaire, 31.25 or less for health perception (the value identifying the first decile in the Bosnia and Era samples for phase 1), and a score of 5 for PTSR.

The primary focus of our study was "physical" health because the background to the study was the controversy around the so-called "Gulf War Syndrome." Pilot work suggested there was considerable resistance among U.K. Gulf veterans to anything that suggested any psychological or stress-related origin to their ill health, and it was clear that using a full traditional measure of PTSD would have had unacceptable consequences to the validity of the study and the response rate. Hence, we chose to use a short measure of PTSD embedded within sections, focusing on more obvious "physical" symptoms. We then created a construct we labeled "posttraumatic stress reaction" (PTSR); the experience of one symptom in each of the 4 classifications-intrusive thoughts, avoidance, arousal, and irritability - and at least 2 additional symptoms of unrefreshing sleep, fatigue, alcohol intolerance, forgetfulness, poor concentration, loss of sexual interest, and decrease in appetite. By the follow-up, we were able to introduce a more formal PTSD assessment, the PTSD Checklist Military Version $(20,21)$. We then showed that our measure of PTSR had a sensitivity of $58.3 \%$, specificity of $94.7 \%$, and positive predictive value of $59.2 \%$ compared with the PTSD Checklist Military Version (cut off 44) (13). 
TABLE 1. Viewing and attitude towards "Warriors" data and results of $\chi^{2}$ analyses between Bosnia and Era groups

\begin{tabular}{lcccrr}
\hline & $\begin{array}{c}\text { Sample } \\
\%(\mathrm{n})\end{array}$ & $\begin{array}{c}\text { Bosnia } \\
\%(\mathrm{n})\end{array}$ & $\begin{array}{c}\text { Era } \\
\%(\mathrm{n})\end{array}$ & \multicolumn{1}{c}{$\chi$} & \multicolumn{1}{c}{$\begin{array}{c}\mathrm{p} \\
\text { value }\end{array}$} \\
\hline Watched "Warriors" $^{4}$ & $45.9(667)$ & $54.1(440)$ & $35 / 6(227)$ & 49.15 & $<.001$ \\
found moving* $^{\prime}$ & $77.3(503)$ & $73.7(319)$ & $84.4(184)$ & 9.51 & .001 \\
found accurate $^{\dagger}$ & $78.0(475)$ & $74.6(315)$ & $85.6(160)$ & 9.00 & .002 \\
\hline
\end{tabular}

* Of those who watched, based on 651 replies.

'Of those who watched, based on 609 replies.

After "Warriors" was televised, we added 3 questions relevant to the TV drama, asking 1) whether respondents had seen the program and whether they found it 2) accurate and/or 3) moving.

Data were analyzed by use of the SPSS version 15. Chisquared test statistics were generated to compare the differences between a) viewers and nonviewers and b) Bosnia viewers and Era viewers on health outcomes before and after the program was televised. We calculated unadjusted and adjusted odds ratios (with 95\% confidence intervals) by using a series of logistic regression models to investigate whether viewing status and group predicted posttransmission health when controlling for sociodemographic variables and phase 1 health status.

\section{RESULTS}

The main results of the epidemiology survey and follow-up study have been extensively reported $(12,14)$. Phase 1 (12) had a response rate of $65.1 \%$, and the follow-up study (15) had a response rate of $71.6 \%$. In this paper, we use only the Bosnia and Era groups because of the baseline differences between these and the Gulf group. Women constituted $21.7 \%$ of the sample for this paper. There were no differences between Bosnia and Era with regard to gender. However, the Bosnia group were younger (mean age $=29.1$ and 34.6 years), and the Era group had achieved higher levels of education (data not shown).
Just less than half of the total sample reported watching "Warriors" (45.9\%; Table 1). Those who had served in Bosnia were more likely to have seen the program, with $54.1 \%$ having watched it in comparison with $35.6 \%$ of the Era group $\left(\chi^{2}=49.15, p<.001, \mathrm{df}=1\right)$. The Era group found it more accurate $(\chi=9.00, p<.01, \mathrm{df}=1)$ and moving $(\chi=9.51, p<.01, \mathrm{df}=1)$ than those deployed to Bosnia, but most still found it both accurate (Bosnia; 74.6\%: Era; 85.6\%) and moving (Bosnia; 73.7\%; Era; 84.4\%).

Viewers and nonviewers did not differ in regard to their educational attainment (Table 2). However, viewers were younger (mean age 30.45 and 32.37 years, $t=4.97$, $p<.001)$ and less likely to be female $\left(\chi^{2}=9.51\right.$ $p=.001)$. There were no gender differences between Bosnia viewers and Era viewers, although Bosnia viewers were younger (mean age 28.73 and 33.76 years, $t=9.37$, $p<.001)$. Educational attainment was significant, with Era viewers having attained higher education levels $(\mathrm{t}=6.03, p=.049)$.

\section{Pretransmission Findings}

There were no statistically significant differences between viewers and nonviewers for phase 1 health perception or common mental disorders before the program was televised (Table 3). Viewers were more likely to be classified as fatigue $\left(\chi^{2}=5.541, p=.011\right)$ and PTSR $\left(\chi^{2}=4.337, p=.023\right)$ cases.

The Bosnia and Era groups were then compared on these measures when the analysis was restricted to those who had watched "Warriors" (Table 4). There were no significant differences between the 2 groups for fatigue, PTSR, or common mental disorders, although Era viewers were more likely to be cases on the health perception measure $\left(\chi^{2}=5.460, p=.015\right)$.

\section{Posttransmission Findings}

Our main hypothesis regarded the effects of watching the program. No significant differences were found between viewers and nonviewers for health perception, fatigue, or

TABLE 2. Sociodemographic details for viewers and nonviewers and for Bosnia viewers and Era viewers

\begin{tabular}{|c|c|c|c|c|c|c|}
\hline & \multicolumn{3}{|c|}{ Full sample } & \multicolumn{3}{|c|}{ Viewers only } \\
\hline & Nonviewers & Viewers & $t / \chi^{2}$ & Bosnia viewers & Era viewers & $t / \chi^{2}$ \\
\hline Age, mean (SD) & $32.37(7.66)$ & $30.45(6.98)$ & $4.97, p<.001$ & $28.73(6.44)$ & $33.76(6.82)$ & $9.37, p<.001$ \\
\hline \multicolumn{7}{|l|}{ Gender, n (\%) } \\
\hline Male & $590(75.2)$ & $546(81.9)$ & & $367(83.4)$ & $179(78.9)$ & \\
\hline Female & $195(24.8)$ & $121(18.1)$ & $9.51, p=.001$ & $73(16.6)$ & $48(21.1)$ & $2.092, p=.091$ \\
\hline \multicolumn{7}{|l|}{ Education, n (\%) } \\
\hline$<$ O levels $/<$ high school & $111(14.6)$ & $105(16.3)$ & & $64(15.1)$ & $41(18.7)$ & \\
\hline O levels/high school & $424(55.9)$ & $383(59.6)$ & & $267(63.0)$ & $116(53.0)$ & \\
\hline$>\mathrm{O}$ levels/college & $224(29.5)$ & $155(24.1)$ & $5.25, p=.072$ & $93(21.9)$ & $62(28.3)$ & $6.03, p=.049$ \\
\hline
\end{tabular}


TABLE 3. Health status of viewers and nonviewers before and after transmission of "Warriors"

\begin{tabular}{|c|c|c|c|c|}
\hline Outcome measure & $\begin{array}{c}\text { Nonviewers } \\
\mathrm{n}(\%)\end{array}$ & $\begin{array}{c}\text { Viewers } \\
\mathrm{n}(\%)\end{array}$ & $\chi^{2}$ & $\begin{array}{c}p \\
\text { value } \\
\end{array}$ \\
\hline \multicolumn{5}{|l|}{ Before transmission } \\
\hline \multicolumn{5}{|l|}{ Health perception } \\
\hline Non-cases & $710(90.6)$ & $598(90.1)$ & 0.103 & .408 \\
\hline Cases & $74(9.4)$ & $66(9.9)$ & & \\
\hline \multicolumn{5}{|l|}{ Fatigue } \\
\hline Noncases & $354(45.3)$ & $259(39.1)$ & 5.541 & .011 \\
\hline Cases & $428(54.7)$ & $403(60.9)$ & & \\
\hline \multicolumn{5}{|l|}{ PTSR } \\
\hline Noncases & $725(92.5)$ & $595(89.3)$ & 4.337 & .023 \\
\hline Cases & $59(7.5)$ & $71(10.7)$ & & \\
\hline \multicolumn{5}{|l|}{$\begin{array}{c}\text { Common mental } \\
\text { disorders }\end{array}$} \\
\hline Noncases & $504(65.2)$ & $416(63.3)$ & 0.548 & .247 \\
\hline Cases & $269(34.8)$ & $241(36.7)$ & & \\
\hline \multicolumn{5}{|l|}{ After transmission } \\
\hline \multicolumn{5}{|l|}{ Health perception } \\
\hline Noncases & $670(87.9)$ & $584(90.1)$ & 1.718 & .110 \\
\hline Cases & $92(12.1)$ & $64(9.9)$ & & \\
\hline \multicolumn{5}{|l|}{ Fatigue } \\
\hline Noncases & $447(60.3)$ & $385(59.6)$ & 0.076 & .413 \\
\hline Cases & $294(39.7)$ & $261(40.4)$ & & \\
\hline \multicolumn{5}{|l|}{ PTSR } \\
\hline Noncases & $696(89.1)$ & $593(89.4)$ & 0.040 & .455 \\
\hline Cases & $85(10.9)$ & $70(10.6)$ & & \\
\hline \multicolumn{5}{|l|}{$\begin{array}{c}\text { Common mental } \\
\text { disorders }\end{array}$} \\
\hline Noncases & $548(73.4)$ & $432(68.5)$ & 3.994 & .026 \\
\hline Cases & $199(26.6)$ & $199(31.5)$ & & \\
\hline
\end{tabular}

PTSR assessed after transmission (Table 3). Viewers were, however, more likely to have common mental disorders $\left(\chi^{2}=3.994, p=.026\right)$ posttransmission. When restricting the analysis to viewers only, we found no differences between Bosnia and Era groups for health perception, PTSR, and common mental disorders. (Table 4). However, Bosnia viewers were more likely to be assessed as fatigue cases $\left(\chi^{2}=3.615, p<.05\right)$.

Using a series of logistic regression models (Table 5), we looked at predictors of posttransmission health. Four sets of models were produced for each of the 4 health outcomes. In the first set of models, viewing status (regardless of group [Bosnia/Era] status) was entered as the independent factor. In the second set of models, we controlled for gender, education, age, and pretransmission health status. In the third and fourth sets of models, the same approach was used but this time with group/viewing status (Bosnia vs Era viewers) as the independent factor, and therefore restricting the analysis to viewers only.

Neither viewing status nor group/viewing status was a significant predictor of posttransmission health in the unadjusted models. In the adjusted models, only
TABLE 4. Health status of Bosnia viewers and Era viewers before and after the transmission of "Warriors"

\begin{tabular}{|c|c|c|c|c|}
\hline Outcome measure & $\begin{array}{c}\text { Bosnia viewers } \\
\mathrm{n}(\%)\end{array}$ & $\begin{array}{c}\text { Era viewers } \\
\mathrm{n}(\%)\end{array}$ & $\chi^{2}$ & $\begin{array}{c}p \\
\text { value }\end{array}$ \\
\hline \multicolumn{5}{|l|}{ Before transmission } \\
\hline \multicolumn{5}{|l|}{ Health perception } \\
\hline Noncases & $403(92.0)$ & $195(86.3)$ & & \\
\hline Cases & $35(8.0)$ & $31(13.7)$ & 5.460 & .015 \\
\hline \multicolumn{5}{|l|}{ Fatigue } \\
\hline Noncases & $167(38.2)$ & $92(40.9)$ & & \\
\hline Cases & $270(61.8)$ & $133(59.1)$ & 0.446 & .279 \\
\hline \multicolumn{5}{|l|}{ PTSR } \\
\hline Noncases & $390(88.8)$ & $205(90.3)$ & & \\
\hline Cases & $49(11.2)$ & $22(9.7)$ & 0.340 & .330 \\
\hline \multicolumn{5}{|c|}{ Common mental disorders } \\
\hline Noncases & $274(63.0)$ & $142(64.0)$ & & \\
\hline Cases & $161(37.0)$ & $80(36.0)$ & 0.060 & .437 \\
\hline \multicolumn{5}{|c|}{ After transmission } \\
\hline \multicolumn{5}{|l|}{ Health perception } \\
\hline Noncases & $389(91.5)$ & $195(87.4)$ & & \\
\hline Cases & $36(8.5)$ & $28(12.6)$ & 2.743 & .066 \\
\hline \multicolumn{5}{|l|}{ Fatigue } \\
\hline Noncases & $239(56.9)$ & $146(64.6)$ & & \\
\hline Cases & $181(43.1)$ & $80(35.4)$ & 3.615 & $<.05$ \\
\hline \multicolumn{5}{|l|}{ PTSR } \\
\hline Noncases & $394(90.4)$ & $199(87.7)$ & & \\
\hline Cases & $42(9.6)$ & $28(12.3)$ & 1.154 & .173 \\
\hline \multicolumn{5}{|c|}{ Common mental disorders } \\
\hline Noncases & $286(69.1)$ & $146(67.3)$ & & \\
\hline Cases & $128(30.9)$ & $71(32.7)$ & 0.214 & .354 \\
\hline
\end{tabular}

group/viewing status became a significant predictor of posttransmission fatigue (adjusted odds ratio, 1.58; 95\% confidence interval, 1.06-2.36). However, when we repeated this analysis with nonviewers (Bosnia nonviewers vs Era nonviewers), a significant difference was also found

TABLE 5. Unadjusted and adjusted odds ratios (Ors) and 95\% confidence intervals $(95 \% \mathrm{CIs})$ for the predictors of posttransmission health status

\begin{tabular}{lcccc}
\hline Posttransmission outcome & OR & $95 \%$ CI & Adj OR* & 95\% CI \\
\hline Health perception & & & & \\
$\quad$ All: viewing status & 0.80 & $0.57-1.12$ & 0.74 & $0.50-1.09$ \\
$\quad$ Viewers only: Era/Bosnia & 0.65 & $0.38-1.09$ & 0.81 & $0.42-1.55$ \\
Fatigue & & & & \\
$\quad$ All: viewing status & 1.03 & $0.83-1.28$ & 0.90 & $0.71-1.15$ \\
$\quad$ Viewers only: Era/Bosnia & 1.38 & $0.99-1.93$ & 1.58 & $1.06-2.36^{\dagger}$ \\
PTSR & & & & \\
$\quad$ All: viewing status & 0.97 & $0.69-1.35$ & 0.77 & $0.53-1.12$ \\
$\quad$ Viewers only: Era/Bosnia & 0.76 & $0.46-1.26$ & 0.79 & $0.43-1.45$ \\
Common mental disorders & & & & \\
$\quad$ All: viewing status & 1.27 & $1.00-1.60$ & 1.24 & $0.96-1.60$ \\
$\quad$ Viewers only: Era/Bosnia & 0.92 & $0.65-1.31$ & 1.02 & $0.67-1.54$ \\
\hline
\end{tabular}

*Adjusted for gender, education $(<\mathrm{O}$ levels/ $<$ high school, O levels/high school, $>\mathrm{O}$ levels/college), age (continuous variable) and pretransmission health status. 'Statistically significant. 
(adjusted odds ratio, 1.59; 95\% confidence interval, 1.11-2.26; data not shown).

\section{DISCUSSION}

The current study investigated the possible effects of watching an accurate program depicting United Nations peacekeeping activities in Bosnia, in a military sample deployed to the region and a nondeployed (Era) military comparison group. We hypothesized that viewing this critically praised and occasionally harrowing dramatic reconstruction would have adverse effects on the mental health of those who watched it, and more specifically, this effect would be found for Bosnia veterans for whom the events were particularly salient (given that they were the subject of the drama), and in those with elevated PTSD scores. None of these predictions were fulfilled. Those deployed to Bosnia were more, not less, likely to watch the program. Those who watched the program had higher, not lower, PTSR levels measured before watching the program. The lack of effect was unlikely to be attributed to failings in the program. Most who watched it found it both moving and accurate. However, it is important to point out that despite the directness and emotional impact of the program, on the veterans who watched it, that the viewers ultimately knew that it was a television drama and not real life. As such it is pertinent that we acknowledge that there is a difference to peoples' response to watching real-life traumatic events as opposed to trauma portrayed in an accurate television drama.

We also hypothesized that there would be health differences between viewers and nonviewers after transmission of the program, but this was only partially supported by the data. Overall, viewers were more likely to have common mental disorders than nonviewers. Bosnia viewers were more likely to be cases on the fatigue measure than Era viewers. No other differences on health outcomes were noted. We also found that neither viewing status nor group/viewing status predicted posttransmission health. The only exception was for fatigue, with Bosnia viewers being more likely to be cases on this measure. However, additional analyses revealed a significant difference for nonviewers in the same direction, and this is likely to reflect a improvement in the Era group and a deterioration in the Bosnia group between assessments points before and after the transmission (15). Therefore, we found little evidence for detrimental effects of watching the program in either Bosnia or Era groups.

The literature to date points to a consensus that PTSD in remission can be reactivated by exposure to a stressful event which resembles the original trauma, in both military (22, 23 ) and civilian populations (24). It has been reported the media coverage of recent conflicts (22) have a similar impact. Vietnam veterans with PTSD were found to exhibit greater physiological responses to scripts of personal combat experiences than those without $\operatorname{PTSD}(25,26)$ and displayed greater arousal after the viewing of a combat as opposed to a noncombat film in comparison with controls (27).

Our findings therefore are in contrast to those, including the International Society for Traumatic Stress Studies, who warn of the impact of media coverage of events for those who have experienced trauma (28). Nevertheless, the advice for those who are distressed by such images to turn off the TV remains common sense (29).

A weakness of our study is the measure used to measure symptoms of traumatic stress. Various focus groups conducted before the study confirmed considerable resistance amongst veterans to anything that suggested any psychological or stress related origin to their ill health. A traditional measure of PTSD would have had unacceptable consequences to the validity of the study and the expected response rate. Our measure of PTSR was therefore a compromise, but we were able to subsequently demonstrate acceptable correlation with another well-validated measure of posttraumatic stress (13). The majority of studies of PTSD rely on questionnaires, with few investigators having the resources to carry out the gold standard diagnostic interviews that are finally required to make the diagnosis of PTSD. Another difference with previous research was that we used a longer time frame than others, and thus perhaps missed more transient effects. But that makes findings of this study more, not less, relevant to determining the final impact of seeing traumatic images (3).

The strength of this study was that unlike many previous studies, participants were not aware that they were participating in an experiment. There is evidence to support a "priming effect" in veterans who may rate themselves in a manner consistent with information given by experimenters or the assumed demands of the experiment (30). In the current study, the information on responses to "Warriors" was collected as part of a follow-up study unconnected with the program, and participants were not aware of the interests of the researchers, not least because when the study started neither were the research team.

Media academics and common experience agree that the impact of any dramatic portrayals on the audience are dependent on the level of realism perceived $(31,32)$, even if it is unclear whether this is more related to the continual repetition of images (drip hypothesis), or more to particular characters, which may have an intense and significant impact on viewers (drench hypothesis). Perhaps "Warriors" failed to achieve the necessary impact; however, anyone who has seen the program would find this hard to accept because most of those who took part in our study found 
that the program was both accurate and moving, so this is an unlikely explanation.

\section{CONCLUSION}

An in-depth, accurate, and emotive TV drama about the stresses of peacekeeping operations in Bosnia had no adverse effect on the mental health of U.K. Armed Forces personnel who watched it. There was no evidence of an adverse effect on those who had served in the deployment depicted in the drama or in those with pretransmission psychological distress. There was no evidence that those with more traumatic stress symptoms avoided watching the program.

\section{REFERENCES}

1. American Psychiatric Association. Diagnostic and Statistical Manual of Mental Disorders: DSM-IV. 4th ed. Washington, DC: American Psychiatric Association; 1994.

2. Simons D, Silveira W. Post-traumatic stress disorder in children after television programs. Br Med J. 1994;308:389-399.

3. Ahern J, Galea S, Resnick H, Vlahov D. Television images and probable posttraumatic stress disorder after September 11: the role of background characteristics, event exposures, and perievent panic. J Nervous Mental Dis. 2004;192:217-226.

4. Bernstein KT, Ahern J, Tracy M, Boscarino JA, Vlahov D, Galea S. Television watching and the risk of incident probable posttraumatic stress disorder. J Nervous Mental Dis. 2007;195:41-47.

5. Otto M, Henin A, Hirshfeld-Becker DR, Pollack MH, Biederman J, Rosenbaum JF. Posttraumatic stress disorder symptoms following media exposure to tragic events: Impact of $9 / 11$ on children at risk for anxiety disorders. J Anxiety Disord. 2007;21:888-902.

6. Kuruppuarachchi K, Williams S, Gadambanathan T. Post-traumatic stress disorder after watching violent scenes on television. Ceylon Med J. 2000;45:177-178.

7. Thacker S. Post-traumatic stress disorder cannot follow television viewing. Br Med J. 1994;308:714.

8. Tucker P, Pfefferbaum B, Nixon S, Dickson W. Predictors of post traumatic stress symptoms in Oklahoma City: exposure, social support, peritraumatic responses. J Behav Health Serv Res. 2000;27:406-416.

9. Propper R, Stickgold R, Keeley R, Christman SD. Is television traumatic? Dreams, stress and media exposure in the aftermath of September 11, 2001. Psychol Sci. 2007;18:334-340.

10. Schuster M, Stein B, Jaycox L, Collins RL, Marshall GN, Elliott MN, et al. A national survey of stress reactions after the September 11, 2001, terrorist attacks. N Engl J Med. 2001;345:1507-1512.

11. Brown M. Obituary of Leigh Jackson. Guardian. March 29 2003.

12. Unwin C, Blatchley N, Coker W, Ferry S, Hotopf M, Hull L, et al. The health of United Kingdom servicemen who served in the Persian Gulf War. Lancet. 1999;353:169-178.

13. Greenberg N, Iversen A, Hull L, Bland D, Wessely S. Getting a peace of the action: measures of post traumatic stress in UK military peacekeepers. J Roy Soc Med. 2008;101:78-84.
14. Hotopf M, David A, Hull L, Ismail I, Palmer I, Unwin C, et al. The health effects of peace-keeping in the UK Armed Forces: Bosnia 1992-1996. Predictors of psychological symptoms. Psychol Med. 2003;33:1-8.

15. Hotopf M, David A, Hull L, Nikalaou V, Unwin C, Wessely S. Gulf War illness-better, worse or just the same? A cohort study. Br Med J. 2003;327:1370.

16. Thomas S, Dandeker C, Greenberg N, Kelly V, Wessely S. "Serving in Bosnia made me appreciate living in Bristol": stressful experiences, attitudes, and psychological needs of members of the United Kingdom Armed Forces. Mil Med. 2006;171:376-380.

17. Chalder T, Berelowitz G, Pawlikowska T, Watts L, Wessely S, Wright D, et al. Development of a fatigue scale. J Psychosom Res. 1993;37:147-153.

18. Goldberg D. The Detection of Psychiatric Illness by Questionnaire. London: Oxford University Press; 1972.

19. Ware J Jr, Sherbourne C. The MOS 36 item short-form health survey (SF-36): conceptual framework and item selection. Med Care. 1992;30:473-483.

20. Blanchard EB, Jones-Alexander J, Buckley TC, Forneris CA. Psychometric properties of the PTSD Checklist (PCL). Behav Res Ther. 1996;34:669-673.

21. Weathers F, Huska J, Keane T. The PTSD Checklist Military Version (PCL-M). Boston, MA: National Center for PTSD; 1991.

22. Long N, Chamberlain K, Vincent C. Effect of the Gulf War on reactivation of adverse combat-related memories in Vietnam veterans. J Clin Psychol. 1994;50:138-143.

23. Solomon Z, Garb R, Bleich A, Grupper D. Reactivation of combat-related posttraumatic stress disorder. Am J Psychiatry. 1987;144:51-55.

24. Burgess A, Holmstrom L. Rape trauma syndrome. Am J Psychiatry. 1974;131:981-986.

25. Kinzie J, Denney D, Riley C, Boehlein J, McFarland B, Leung P. A crosscultural study of reactivation of posttraumatic stress disorder symptoms; American and Cambodian psychophysiological responses to viewing traumatic video scenes. J Nervous Mental Dis. 1998;186:670-676.

26. Pitman R, Orr S, Forgue D, de Jong J, Claiborm J. Psycho physiologic assessment of posttraumatic stress disorder imagery in Vietnam combat veterans. Arch Gen Psychiatry. 1987;44:970-975.

27. Pitman R, Orr S, Forgue D, Altman B, de Jong J, Herz L. Psychophysiologic responses to combat imagery of Vietnam veterans with posttraumatic stress disorder versus other anxiety disorders. J Abnormal Psychol. 1990;99:49-54.

28. International Society for Traumatic Stress Studies (ISTSS) website: Information for the Media-"What does the news industry need to know about the science related to the survivors, the public and news consumption?" Available at: http://www.istss.org/AM/Template.cfm?Section = Informationforthe Media\&Template $=/ \mathrm{CM} /$ ContentDisplay.cfm\&ContentID $=1638$. Accessed April 19, 2011

29. Kinzie JD, Boehnlein M, Riley C, Sparr L. The effects of September 11 on traumatized refugees: reactivation of posttraumatic stress disorder. J Nervous Mental Dis. 2002;190:437-441.

30. LaGuardia RL, Smith G, Francois R, Bachman L. Incidence of delayed stress disorder among Vietnam era veterans: The effect of priming on response set. Am J Orthopsychiatry. 1983;53:18-26.

31. Mo Bahk C. Drench effects of media portrayal of fatal virus disease on health locus of control beliefs. Health Commun. 2001;13:187-204.

32. Reep DC, Dambrot FH. Effects of frequent television viewing on stereotypes: 'Drip, drip' or 'drench'? Journalism Q. 1989;66:543-557. 